\title{
Self-Organization during Friction of Slide Bearing Antifriction Materials
}

\author{
Iosif S. Gershman ${ }^{1, *}$, Alexander E. Mironov ${ }^{1}$, Eugeniy I. Gershman ${ }^{1}$, \\ German S. Fox-Rabinovich ${ }^{2}$ and Stephen C. Veldhuis ${ }^{2}$ \\ Received: 29 May 2015; Accepted: 25 November 2015; Published: 4 December 2015 \\ Academic Editor: Kevin H. Knuth \\ 1 Joint Stock Company Railway Research Institute, 3rd Mytischinskaya Street 10, Moscow 107996, Russia; \\ juliadosby@hotmail.com (A.E.M.); Gershmanei@gmail.com (E.I.G.) \\ 2 Department of Mechanical Engineering, McMaster University, Hamilton, ON L8S4L7, Canada; \\ gfox@mcmaster.ca (G.S.F.-R.); veldhu@mcmaster.ca (S.C.V.) \\ * Correspondence: isgershman@gmail.com; Tel.: +1-905-525-9140
}

\begin{abstract}
This article discusses the peculiarities of self-organization behavior and formation of dissipative structures during friction of antifriction alloys for slide bearings against a steel counterbody. It shows that during self-organization, the moment of friction in a tribosystem may be decreasing with the load growth and in the bifurcations of the coefficient of friction with respect to load. Self-organization and the formation of dissipative structures lead to an increase in the seizure load.
\end{abstract}

Keywords: friction; sliding; coefficient; running-in; self-organization; non-equilibrium thermodynamics

\section{Introduction}

Each system and regime of friction has its own specific features, which depend on both the application and the purpose of the friction system. To select a theory applicable to every tribosystem, some generic features typical of all tribosystems should be outlined. It is known that wear is a generic characteristic of any tribosystem. Wear varies within a wide range; a large variety of different wear mechanisms exist, but the wear process is an attribute of friction. According to Klamecki [1], wear is a fundamental characteristic of friction.

The same, according to Klamecki [2] and Bershadsky [3], could be said about the formation of modified structures on friction surfaces, also known as secondary structures. Stabilization of the parameters of friction at the running-in stage is accompanied by the formation and stabilization of these secondary structures. Thus, secondary structures carry out protective functions, limit the depth of interaction between frictional bodies, and prevent direct contact. The greater part of friction energy is accumulated within the secondary structures [4]. Therefore, the secondary structures are a steady zone of primary energy dissipation.

Wear and formation of secondary structures are fundamental processes for any frictional couple. This is the reason why friction is considered to be based on the fundamental laws of nature [5]. As friction involves energy transformation, it would be natural to approach it from a thermodynamic standpoint. Friction is a typical non-equilibrium process and its relationship with non-equilibrium thermodynamics and self-organizing concepts will be considered from the viewpoint of Prigogine's theory [6].

In [7] it is shown that under self-organization in a tribosystem, the wear rate decreases. Some researchers [8-10] have analyzed self-organizing processes in tribosystems associated with current collection, machining of metals, and in relation to the catalytic effects during friction. 
It is generally assumed [11] that self-organization consists of the formation of dissipative structures [12]. According to [6], dissipative structures are organized states which originate spontaneously within a system under strongly non-equilibrium conditions due to the interchange of matter and energy with the medium. Therefore, by contrast to equilibrium structures (such as crystals), dissipative structures represent a process which is stable within a certain range of variability and characterized by negative entropy production. This means that, for example, the phase changes and chemical reactions specific for dissipative structures will increase the free energy.

Examples in tribology of such processes are: formation of martensite in surface layers of steel with unstable austenite during friction (Bogachev-Mintz effect) [10]; chemical reaction of carbon reduction from carbon dioxide by copper during the friction of copper [13]; selective transfer of light or heavy elements towards the friction surface, depending on the friction regime in nanostructural coatings of cutting tools [14], formation of protective films on the friction surfaces of lead and tin bronzes and other antifriction alloys [15]. Methods found in non-equilibrium thermodynamics possess potential applications for fundamental study of friction and wear and development of new (e.g., self-lubricating) materials [16].

These are not spontaneous processes; that is, they do not naturally occur upon achieving a certain temperature, concentration, or pressure. Energy is required for the processes to happen. When displaced from equilibrium, the system may lose the state of thermodynamic stability. This may be accompanied by self-organization and formation of dissipative structures, leading to a spontaneous onset of steady non-equilibrium processes. Some part of the friction energy will then be spent for these non-equilibrium processes, i.e., to create and to maintain dissipative structures. The portion of friction energy that would have gone into damaging the surface and causing wear will be reduced respectively. Consequently, the formation of dissipative structures during friction should lead to lower wear rates.

Indeed, the formation of the dissipative structures listed above results in drastic reduction in the wear rates, normally by several times [11].

Formation of dissipative structures (self-organization) may be accompanied by newly originating relationships between the friction parameters that did not exist before self-organization. This corresponds to the concept of structure [17]. The lubricating effect of current in sliding electrical contacts provides an example of such relationships between the friction parameters [18].

As an example of the reduction of the friction coefficient as load is increased during self-organization, this article focuses on the formation of dissipative structures in anti-friction alloys for slide bearings.

Tin bronze was selected for testing as a traditional material for slide bearings. It is known that tin bronze exhibits anti-friction properties due to the segregation of tin as a soft fusible element $[3,15]$. The authors have repeatedly observed precipitation of tin on the sliding surfaces in tin bronze bearings of various friction units that operated in near seizure mode. However, according to the equilibrium diagram, tin is included in the composition of the solid solution, i.e., equilibrium thermodynamics prohibits the precipitation of tin from a solid solution. In this way, nonequilibrium thermodynamics provides an explanation for tribological effects via the precipitation of tin from a solid solution.

\section{Thermodynamic Analysis of Frictional Phenomenon}

Similar to [7,19], let us consider a system that consists of one friction body and a source of energy in the friction zone. Let us assume that the energy source has no mass and is therefore entropy-free [20]. In the system we will consider, the entropy change is associated with one body. Entropy of the friction body may be changed by the transfer of heat from the source to the body, mechanical work on the friction body, accession of chemical substances with their own entropies, etc., i.e., by external actions- the entropy flux $\left(d S_{e}\right)$. 
Entropy of the body may change due to the production of entropy through the passage of heat and other flows along the body and through physical and chemical processes occurring internally $\left(d S_{i}\right)$. The portion of entropy caused by the heat exchange with the source leads to an increase in the entropy as heat passes from a hotter source to a colder body.

According to the second law of thermodynamics, the entropy production is positive $\left(d S_{i}>0\right)$. Therefore, the listed effects increase the body's entropy. However as self-organizing processes develop, a body's entropy is bound to become lower (at the same level of inner energy) than under the same conditions in the absence of self-organization [21]. In [11] it is demonstrated that the entropy production with self-organization is lower than a system's entropy production without it, under the same conditions. The reduction of the body's entropy production during friction may be explained by the process of wear. According to $[1,2,4,5]$, wear leads to an increase in entropy, i.e., during wear, the distribution of matter in the thermodynamic system occurs. This is due to the fact that in $[1,2,4,5]$ the rubbing body and the environment is a thermodynamic system. In our work, one rubbing body is a thermodynamic system, which loses its mass and, hence, reduces its entropy during wear.

During friction, the body's entropy production may be decreasing not only because of wear (i.e., loss of matter) but also because of transformations taking place in the surface layers of the contacting materials. The formation of secondary structures may be accompanied by negative or positive entropy production. Let us examine both variants.

The change in a friction body's entropy $(d S)$ will consist of the following constituents:

$$
d S=d S_{e}+d S_{i}+d S_{f}-\left|d S_{S}\right|
$$

where $d S_{e}$ is the entropy flux excluding wear; $d S_{i}$ is the entropy production excluding friction surface transformations; $d S_{f}$ is the portion of entropy production associated with friction surface transformations $\left(d S_{f}>0\right.$ for spontaneous transformations and $d S_{f}<0$ for nonspontaneous transformations); and $d S_{S}$ is the entropy change in a friction body due to the wearing of its base.

According to the second law of thermodynamics, the total entropy production should be positive:

$$
d S_{i}+d S_{f}>0
$$

The value of $d S_{s}$ is always negative because the matter is carried away by wear, which removes its respective entropy from the system.

The above discussion suggests that $d S_{e}>0$. According to the second law of thermodynamics, $d S_{i}>0$. The value of $d S_{f}$ may be negative or positive. For example, during formation of solid solutions or stoichiometric chemical compositions corresponding to the stable state diagrams, $d S_{f}>0$. During formation of structural and phase constituents not present on the state diagrams or during chemical reactions with negative chemical affinity, $d S_{f}<0$.

The sum of $d S_{f}$ and $d S_{i}$ represents the total entropy production, so even with a negative value of $d S_{f}$ :

$$
d S_{i}-\left|d S_{f}\right|>0
$$

In the stationary state, the entropy change rate will be zero. Differentiating Equation (1) with respect to time, we get:

$$
\frac{d S}{d t}=\frac{d S_{e}}{d t}+\frac{d S_{i}}{d t}+\frac{d S_{f}}{d t}-\frac{d S_{s}}{d t}=0
$$

In the case of spontaneous transformations $\left(\frac{d S_{f}}{d t}>0\right)$, Equation (4) suggests that:

$$
\frac{d S_{s}}{d t}(e q)=\frac{d S_{e}}{d t}+\frac{d S_{i}}{d t}+\left|\frac{d S_{f}}{d t}\right|
$$

where $e q$ denotes a spontaneous process. 
In the case of nonspontaneous transformations $\frac{d S_{f}}{d t}<0$, Equation (4) suggests that:

$$
\frac{d S_{s}}{d t}(\text { noneq })=\frac{d S_{e}}{d t}+\frac{d S_{i}}{d t}-\left|\frac{d S_{f}}{d t}\right|
$$

where noneq denotes a nonspontaneous process.

By comparing Equations (5) and (6), we will get:

$$
\frac{d S_{s}}{d t}(\text { noneq })<\frac{d S_{s}}{d t}(e q)
$$

From Equations (5)-(7), and entropy additively, it follows that the wear rate during nonspontaneous transformations in secondary structures is lower than the wear rate during spontaneous transformations in secondary structures. Furthermore, the wear rate increases as the entropy production grows.

Consequently, during self-organization, when non-spontaneous processes become active with negative entropy production, other factors being equal, the total entropy production will be lower than the total entropy production in a system without self-organization. This results in lower wear rates.

The known self-organizing processes during friction, such as for example, the lubricating effect of current [8], subnormal friction [9], and the Bogachev-Mintz effect [10], lead to a sudden abrupt reduction of the wear rate by several times.

As the regimes of friction become more severe (after self-organization and formation of dissipative structures), spontaneous processes intensify, increasing total entropy production, but at the same time nonspontaneous processes intensify as well, decreasing total entropy production.

During the running-in stage, as the regimes of friction are becoming more stringent, (such as under the increase of load), the friction parameters (friction coefficient, temperature, wear rate) may decrease and stabilize [22]. When this happens, according to [23], entropy production should decrease. Therefore, the condition of theorem [24] is as follows: if the entropy production decreases as thermodynamic forces and flows are changed, then it will reach the minimum and will not alter with further changes in the forces and flows. This happens due to non-spontaneous processes.

Entropy production during friction is equal to [7]:

$$
\frac{d_{i} S}{d t}=\frac{(k p v)^{2}}{B^{2} T^{2} \lambda}
$$

where $k$ is the friction coefficient, $p$ is pressure, $v$ is slip velocity, $B$ is nominal contact area, $T$ is absolute temperature, and $\lambda$ is thermal conductivity.

According to the theorem in [24], let us consider a condition where the entropy production remains constant as the load increases:

$$
\frac{d_{i} S}{d t}=\frac{(k p v)^{2}}{B^{2} T^{2} \lambda}=C
$$

where $\mathrm{C}$ is constant.

From Equation (9) it follows that:

$$
k=\frac{T B \sqrt{C \lambda}}{p v}
$$

From Equation (10) it follows that after self-organization, the friction coefficient may decrease as the load increases. Equation (10) is similar to the equation that describes the friction coefficient reduction in the "lubricating effect of current" [7]. 
Equation (10) also implies that increased temperature may lead to increased friction coefficients, possibly resulting in seizure. However, the dependency of the friction coefficient will be determined not only by the load and temperature, but also by the changes in the thermal conductivity with the changing friction parameters, primarily temperature. The change in thermal conductivity during friction will be determined by the chemical composition of secondary structures that have formed. Considering that on bronze friction surfaces the concentrations of tin and zinc are increasing and copper is decreasing, the thermal conductivity of these secondary structures will be lower than the thermal conductivity of the surface layers of bronze before friction. A subnormal thermal conductivity of secondary structures was noted, for example, in [25].

The mechanism of the "lubricating effect of current" consists of a nonspontaneous negative affinity chemical reaction of carbon reduction by copper from carbon dioxide, which occurs on the friction surface [26]. The mechanism that accounts for the decreasing friction coefficient of antifriction alloys under an increase of load, i.e., nonspontaneous processes on that friction surface, will demand further investigation. In particular, further research is required on the secondary structures formed on the friction surfaces.

\section{Results and Discussion}

At a load of $1470 \mathrm{~N}$, the initial oil temperature was $18{ }^{\circ} \mathrm{C}$. After 3000 rotations of the roller, moment of friction and oil temperature variations ceased to be noticeable. At that time the oil temperature was $24^{\circ} \mathrm{C}$ and the moment of friction was $2.035 \mathrm{~N} \cdot \mathrm{m}$. After 12,000 rotations the moment of friction decreased to $1.11 \mathrm{~N} \cdot \mathrm{m}$ and the oil temperature increased to $34-35^{\circ} \mathrm{C}$. The test was ended after 2,600,000 rotations of the roller at a moment of friction of $1.295 \mathrm{~N} \cdot \mathrm{m}$ and an oil temperature of $34-35^{\circ} \mathrm{C}$.

At a load of $2940 \mathrm{~N}$, the initial oil temperature was $18^{\circ} \mathrm{C}$. The oil was not additionally heated. After 6000 rotations of the roller, moment of friction and oil temperature variations ceased to be noticeable. At that time the oil temperature was $41{ }^{\circ} \mathrm{C}$ and the moment of friction was $1.11 \mathrm{~N} \cdot \mathrm{m}$. After 10,000 rotations the moment of friction was $1.11 \mathrm{~N} \cdot \mathrm{m}$ and the oil temperature decreased to $34-35{ }^{\circ} \mathrm{C}$. The test was ended after 2,443,000 rotations of the roller at a moment of friction of $1.48 \mathrm{~N} \cdot \mathrm{m}$ and anoil temperature of $34-35^{\circ} \mathrm{C}$.

At a load of $2940 \mathrm{~N}$, the initial oil temperature was $42{ }^{\circ} \mathrm{C}$ because of additional preheating. After 7500 rotations of the roller, moment of friction and oil temperature variations ceased to be noticeable. At that time the oil temperature was $75{ }^{\circ} \mathrm{C}$ and the moment of friction was $1.11 \mathrm{~N} \cdot \mathrm{m}$. After 20,100 rotations the moment of friction was $1.11 \mathrm{~N} \cdot \mathrm{m}$ and the oil temperature had decreased to $71^{\circ} \mathrm{C}$. The test was ended after 2,477,700 rotations of the roller at the moment of friction of $1.295 \mathrm{~N} \cdot \mathrm{m}$ and the oil temperature of $78^{\circ} \mathrm{C}$.

At a load of $2940 \mathrm{~N}$ the initial oil temperature was $70{ }^{\circ} \mathrm{C}$ because of additional preheating. No steady state friction regime was observed. The oil temperature and the moment of friction were constantly increasing. After 1000 rotations of the roller, a seizure occurred.

The friction coefficient values at different loads and same initial oil temperatures are shown in Figure 1. The friction coefficient values at different initial temperatures and same loads are shown in Figure 2. 


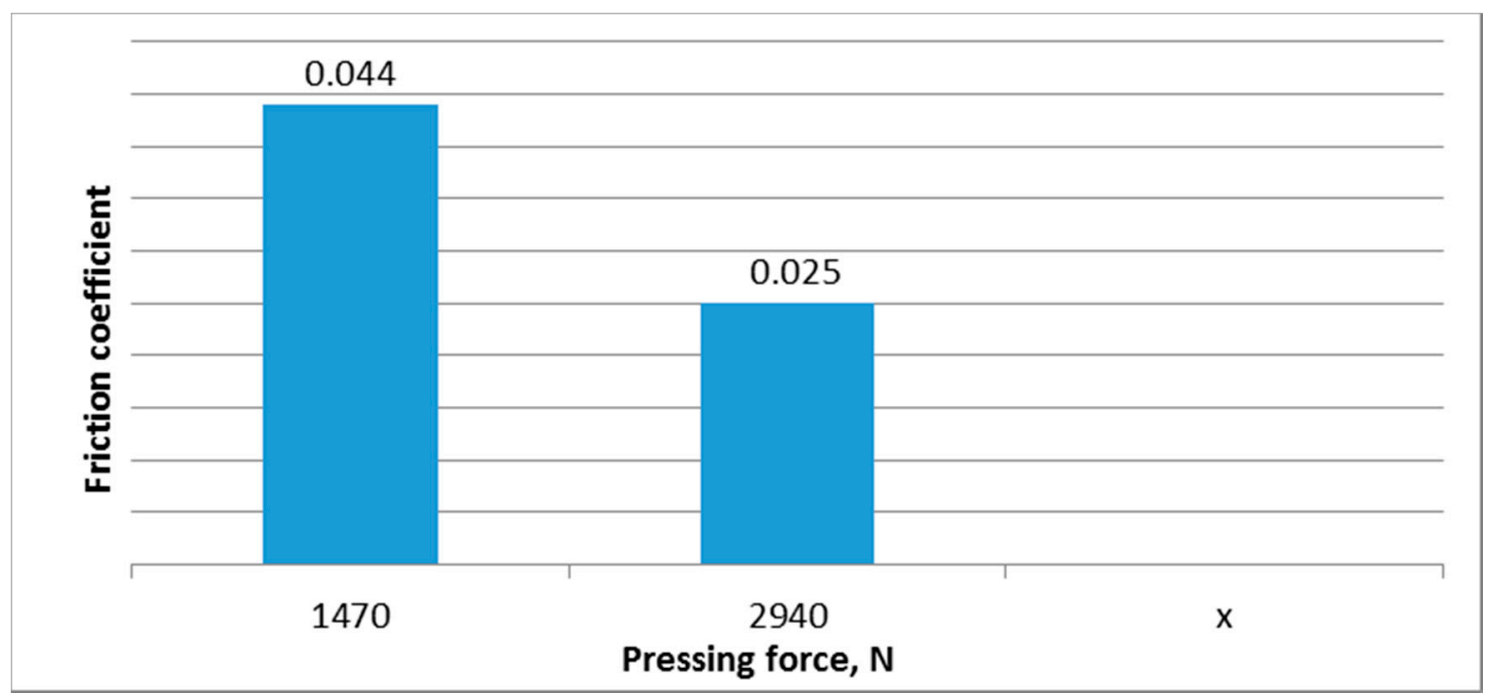

Figure 1. Bronze on steel friction coefficients for different loads and same initial oil temperature.

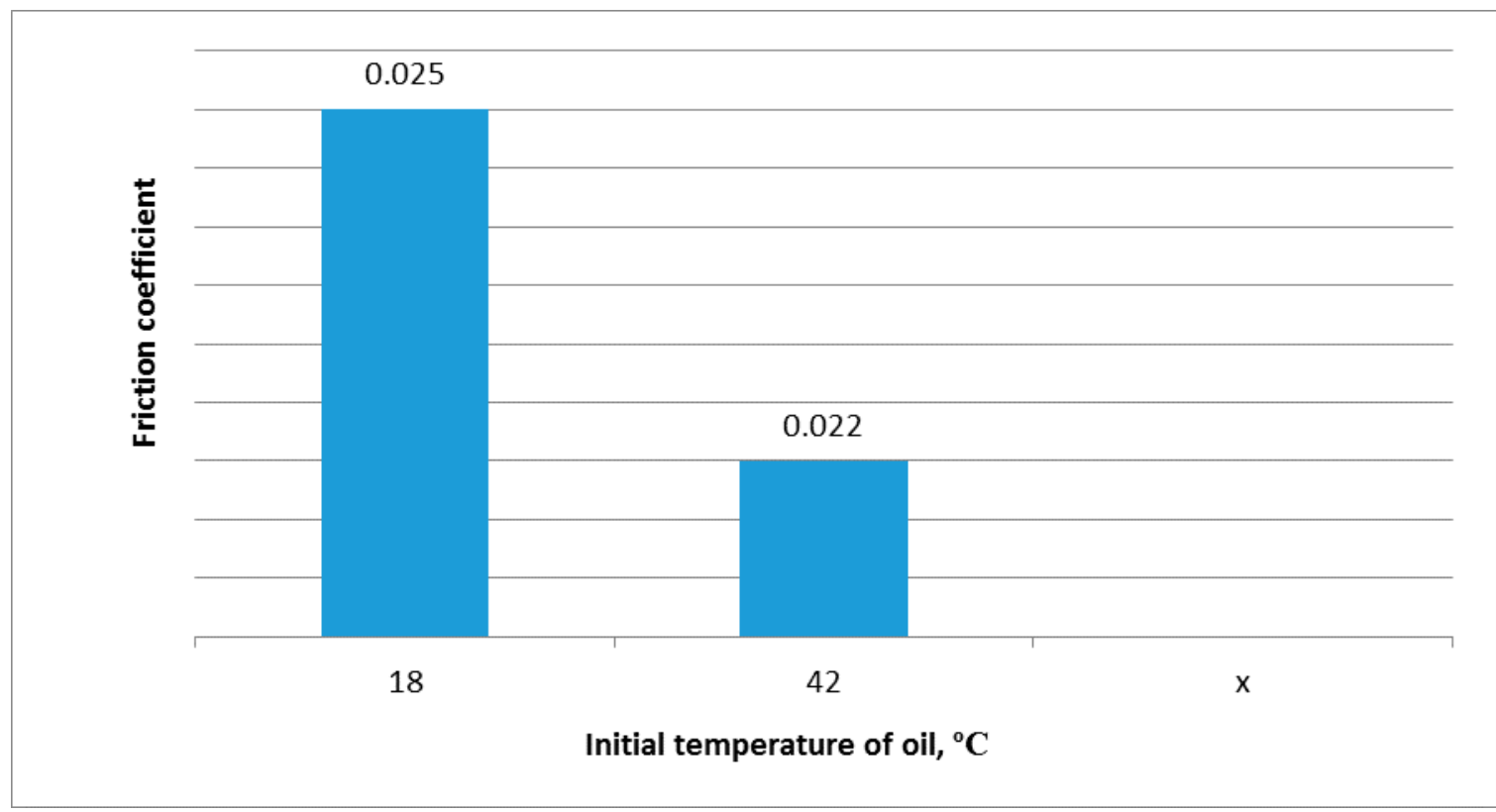

Figure 2. Bronze on steel friction coefficients for different initial oil temperatures and same load.

Figure 1 suggests that the friction coefficient is reduced as the load is increased at the same initial oil temperatures. Figure 2 suggests that the friction coefficient is reduced as the initial oil temperature is raised at the same load. The following observations may be made from the experiments:

- Identical values of the steady-state moment of friction were observed for the three couples under test (except for the last one).

- At a lower test load, the tribosystem needed more time to stabilize the moment of friction and the oil temperature.

- Higher oil temperatures after additional preheating resulted in slower stabilization of the moment of friction and the oil temperature, although quite the opposite effect was expected before the tests.

- The experimental data suggest that the moment of friction is decreased as the load is increased. 
- Increasing the initial oil temperature up to $70{ }^{\circ} \mathrm{C}$ leads to seizure under the load at which no seizure was observed with lower initial oil temperatures.

- Increasing temperature at an invariable load results in a decreasing friction coefficient.

During the running-in of antifriction alloys for slide bearings, the load should be increased gradually (in steps). As the load is increased at a given step, the moment of friction abruptly grows. Then it gradually decreases and stabilizes at a given load down to a value exceeding the moment of friction of the previous load. This tendency of the moment of friction is usually observed before the end of the running-in, provided there is no seizure. Figure 3 shows the dependence of the coefficient of friction on load applied during the tests, in order to determine the seizure load during friction of steel contacting bronze under drip feed oil. The results of three test specimens are shown. As it follows from Figure 3, the seizure load for samples 2 and 3 is $980 \mathrm{~N}$, and the corresponding load setting for sample 1 is $1441 \mathrm{~N}$. It should be remarked that the coefficient of friction diminishes with increasing loads, up to the point of seizure. This confirms the conclusions of Equation (10).

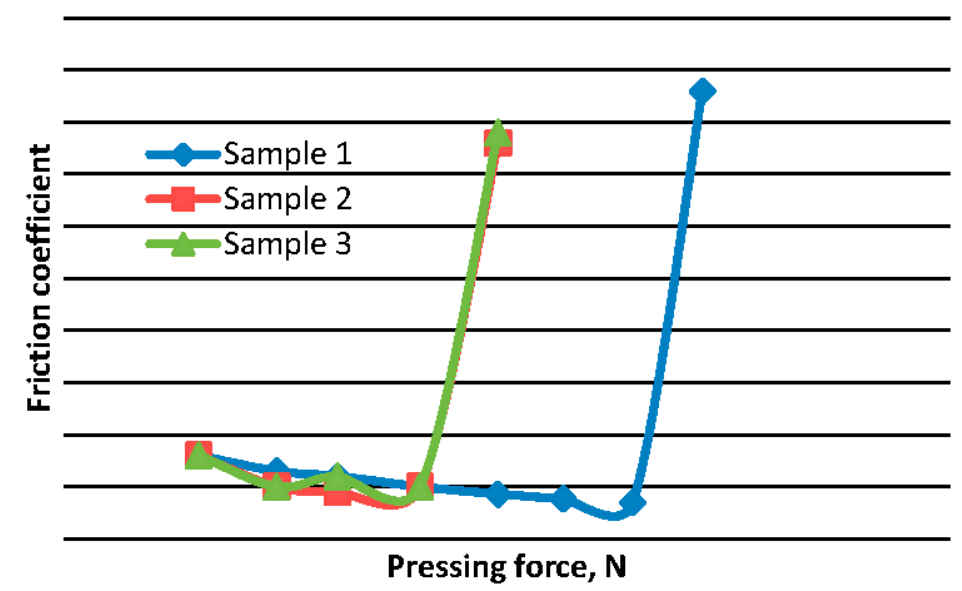

Figure 3. Dependence of the coefficient of friction vs. load during the tests to determine the seizure load during friction of bronze on steel with drip feed oil.

Given that the three samples (Figure 3) are three friction surfaces made of the same bronze, one can assume that at the load of $804 \mathrm{~N}$, a bifurcation occurs in the curve of the coefficient of friction vs. load. In Sample 1, dissipative structures are formed. It is possible to confirm this by observing structures on the friction surfaces.

What we see in our case is stabilization of the moment of friction, which ceased to change under an increasing load (it should be noted that the duration of the test was considerably longer than the duration of one step of the running-in phase). This means that the friction coefficient decreases as the load grows.

A new relationship develops between the friction parameters, load and friction coefficient. This is characteristic of a structure. Considering the non-equilibrium state of the friction system, such a relationship may correspond to dissipative structures.

This is confirmed by microstructural studies of bronze friction surfaces using scanning electron microscope (SEM).

Figure 4 shows the evolution of tin on bronze surfaces with different friction conditions, typical for all samples prior to the first seizure load (Figure 3). Figure 4a shows the characteristic distribution of tin on the surface of bronze before friction. Tin is included in the composition of the solid solution based on copper in concentrations of $6 \%-8 \%$ by weight. Areas not occupied by the tin represent a lead or solid solution of zinc in copper. 
Figure $4 \mathrm{~b}$ shows the distribution of tin on the surface of bronze after fluid friction. Tin is a solid solution of the same concentration. The region occupied by the solid solution of tin in copper on the friction surface grows larger.

Figure $4 \mathrm{c}$ shows the distribution of tin on the surface of bronze after the initial boundary friction. The solid solution of tin in the copper covers the entire friction surface. The friction surface is characterized by the appearance of two types of solid solutions-primary $(6 \%-8 \% \mathrm{Sn})$ and the new rich $(30 \%-35 \% \mathrm{Sn})$. The images and elemental compositions were determined by an X-ray microprobe SEM (CAMEBAX-SX50, Cameca, Gennevilliers, France).

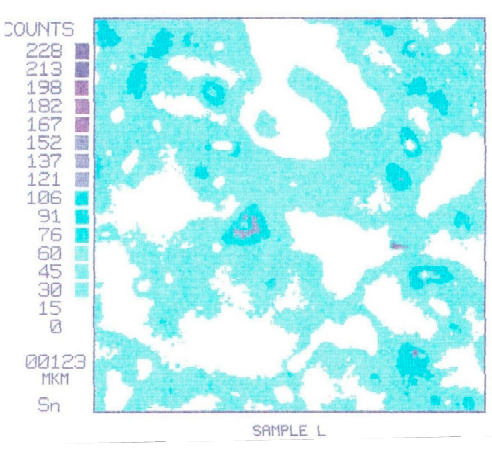

(a)

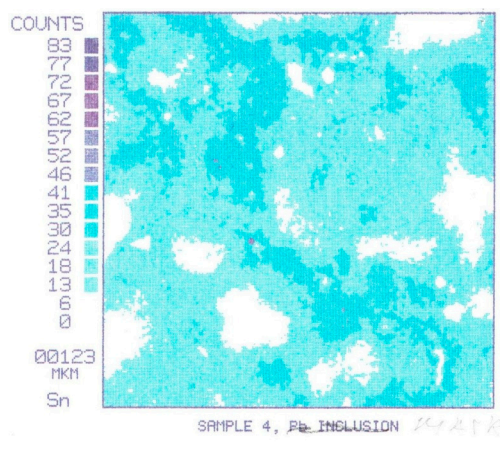

(b)

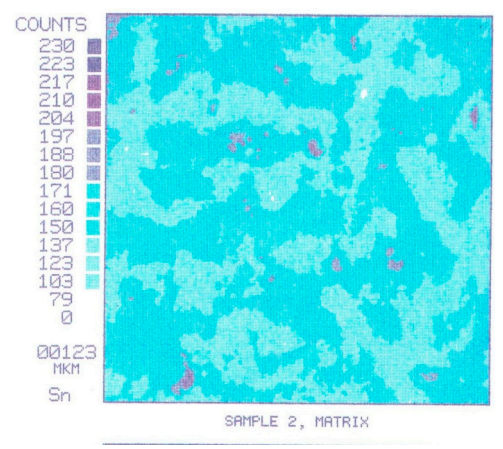

(c)

Figure 4. Evolution of tin on bronze surfaces with different friction conditions (square side length is 123 microns): (a) characteristic distribution of tin on the surface of bronze before friction; (b) distribution of tin on the surface of bronze after fluid friction; (c) distribution of tin on the surface of bronze after the initial boundary friction.

Figure 5 shows the distribution of tin on the friction surface of the sample, which behaved in the same way as sample 1 (Figure 3) after a test at a load of $1000 \mathrm{~N}$ before seizure. Tin segregated from solid solution to form separate inclusions.

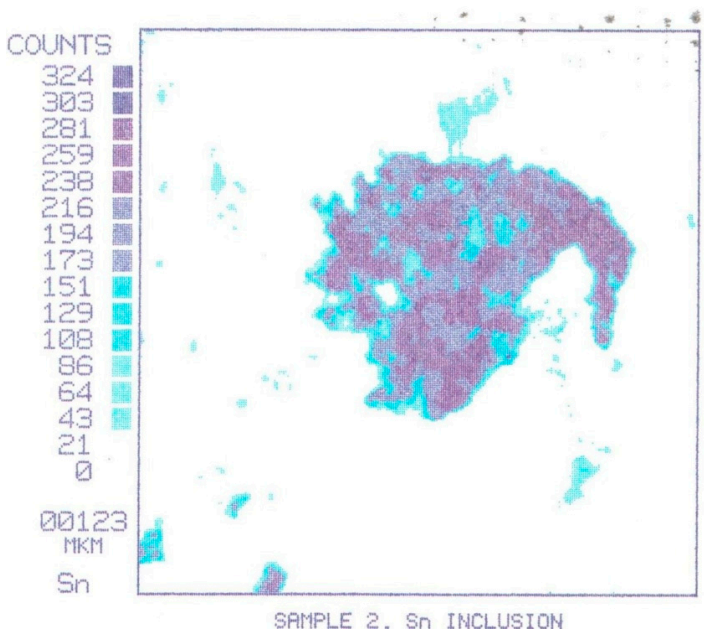

Figure 5. Distribution of tin on the surface of the friction mode before seizure. Square side length is 123 microns.

Figure 6 shows the distribution of tin on the friction surface of the sample, which behaved in the same way as sample 1 (Figure 3 ) at the beginning of seizure. Inclusions of tin are smeared with a thin film (thickness $1 \mu \mathrm{m}$ ) on the friction surface. This prevents catastrophic seizure. If tin is not released from the solid solution, catastrophic seizure occurs at relatively low loads. 


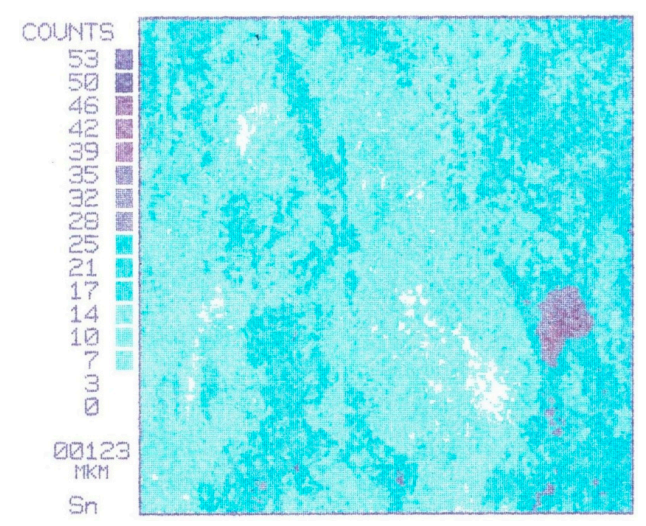

Figure 6. Distribution of tin on the friction surface at the beginning of seizure. Square side length is 123 microns.

The structure shown in Figure 4c is typical for the friction surfaces of all three samples after testing under a load of $804 \mathrm{~N}$ (bifurcation point, Figure 3). The structure shown in Figure 5 is typical for the friction surface of sample 1 after testing under loads of 980-1127 N (Figure 3). The structure shown in Figure 6, is typical for a friction surface of sample 1 after testing under a load of $1284 \mathrm{~N}$ (Figure 3). Tin has a relatively low melting point and high plasticity, so it serves as a solid lubricant in sliding copper on steel. Tin on the copper surface prevents seizure. Figure $4 \mathrm{c}$ shows the separation of the solid solution of tin in copper with the formation of "pre-nucleuses" of tin segregation (portions of a solid solution with $30 \%-35 \% \mathrm{Sn}$ ). On the friction surface of samples 2 and 3, the tin is not segregated from the solid solution, therefore seizure was observed at a load of $980 \mathrm{~N}$ (Figure 3). Figure 5 shows the segregation of tin from the solid solution on the friction surface of sample 1 after a test under a load of $980 \mathrm{~N}$. Tin segregated from the solid solution. Therefore, there was no seizure under a $980 \mathrm{~N}$ load (Figure 3). Tin then spread across the friction surface and its concentration decreased (Figure 6). Therefore, under a $1441 \mathrm{~N}$ load, seizure occurred in sample 1 (Figure 3). Thus, if tin is segregated from the solid solution of $\mathrm{Cu}$, the seizure load is shifted to larger values (sample 1 , Figure 3). Conversely, if tin is not segregated from the solid solution, the seizure load is shifted to the smaller values (samples 2 and 3, Figure 3).Given that the same testing conditions were used for samples 1, 2 and 3, it can be assumed that the segregation of a solid solution of tin is a random process, and $804 \mathrm{~N}$ (see Figure 3) is a bifurcation point. Segregation of tin from the solid solution of copper does not correspond to the equilibrium phase diagram of $\mathrm{Cu}-\mathrm{Sn}$. Therefore, segregation of tin from the solid solution is a non-spontaneous process and is accompanied by an increase in free energy and negative entropy production. This process occurs under far from equilibrium conditions resulting in entropy decrease. Therefore, it can be regarded as a process of self-organization with the formation of dissipative structures. According to [6], the process of self-organization and the formation of dissipative structures can occur only after the loss of thermodynamic stability of the system. The loss of thermodynamic stability is a random process according to the conditions of Lyapunov's theorem. Thus, self-organization and the formation of dissipative structures is also a probabilistic process [6]. Self-organization is a random process that is characterized by the presence of a bifurcation. After the bifurcation point the process can go along the so-called "thermodynamic branch (samples 2 and 3, Figure 3)" or by the way of formation of dissipative structures (sample 1, Figure 3).

The microstructural investigation results of the friction surfaces show that each friction mode is characterized by inherent secondary structures. Moreover, hard regimes leading to friction processes are not specific to the diagrams for the equilibrium state. This is confirmed by the passage of non-spontaneous physical and chemical processes on the friction surfaces.

Consequently, we can talk about the occurrence of self-organization and the formation of dissipative structures. This reduces the coefficient of friction under an increasing load, reduces the 
temperature in the zone of friction, reduces the wear rate, and improves resistance to seizure. Such behavior is typical for all types of bronze containing $\mathrm{Sn}, \mathrm{Pb}$, and $\mathrm{Zn}$.

\section{Experimental Section}

The tests were conducted on a friction machine in a "shoe-and-roller" design. The oil was kept in a special bath in which the lower part of a rotating steel roller was permanently dipped. The experimental setup is shown in Figure 7. The oil used was "Shell Rimula R2 + 40".

The shoe was made of bronze with $4 \%$ (mass) Sn, $4 \%$ (mass) $\mathrm{Zn}$, and $17 \%$ (mass) $\mathrm{Pb}$. The hardness of the bronze was found to be $84 \mathrm{HB}$. The shoe had 5 independent working surfaces. The corner radius of the working surfaces was $23 \mathrm{~mm}$; the shoe's length was $10 \mathrm{~mm}$. Each of the working surfaces was run-in for $3 \mathrm{~h}$ before testing. A new working surface was used for each test.

The counter-body was shaped like a roller and manufactured from 1045 steel. The rollers were $46 \mathrm{~mm}$ in diameter and $10 \mathrm{~mm}$ wide. The working surface of the rollers was polished before testing. The rotation speed of the rollers was $500 \mathrm{rpm}$.

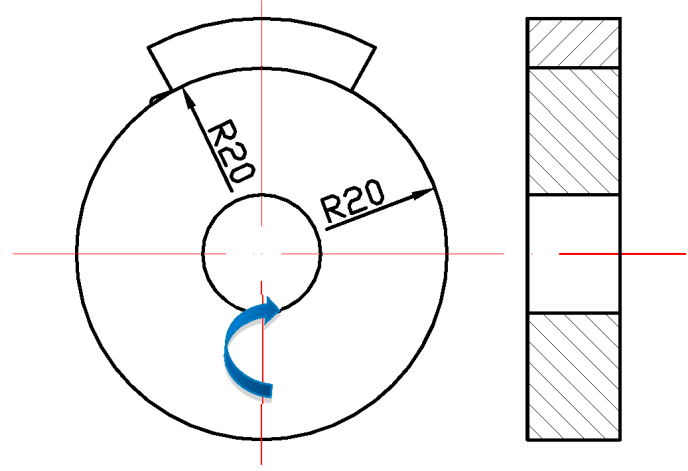

Figure 7. Test set up of the frictional test of bronze on steel.

The values monitored during the tests were: oil bath temperature at the friction zone outlet, rotation speed of the roller (slip distance), and moment of friction. The tests were conducted at loads of $1470 \mathrm{~N}$ and $2940 \mathrm{~N}$ without additional preheating of oil and at a load of $2940 \mathrm{~N}$ with additional preheating of oil.

According to the experimental setup shown in Figure 7, frictional testing was performed with increasing load to determine the seizure load for bronze. The oil was applied drop wise to the friction zone, two drops per minute $(0.002 \mathrm{~L} / \mathrm{h})$. Prior to testing, the frictional pair was run-in with a minimal load of $304 \mathrm{~N}$ until the contact area reached of $90 \%$ of the nominal area. During the test, the load was increased by $137-187 \mathrm{~N}$ every $10 \mathrm{~min}$. Tests were conducted up to the load at which seizure occurred (increasing the coefficient of friction by several times).

\section{Conclusions}

Application of non-equilibrium thermodynamics and self-organization theory to friction has demonstrated a possibility of reducing the friction coefficient under an increased load. Reduction of the friction coefficient of an antifriction bronze/steel couple in reverse proportion to the load has been confirmed by experiment.

Reduction of the friction coefficient of an antifriction bronze/steel couple with the temperature approaching its critical seizure value has been demonstrated. During sliding of tin bronze on steel, self-organization is possible, as evidenced by the reduction of the coefficient of friction under an increasing load and in the bifurcations of the coefficient of friction with respect to load. Self-organization and the formation of dissipative structures lead to an increase in the seizure load. The mechanism of self-organization and the formation of dissipative structures is the segregation 
of tin from a Cu-based solid solution on the friction surfaces of the bronze. Once tin is segregated, the load which results in seizure onset increases; if tin does not segregate, the seizure load is lower. According to the equilibrium phase diagram of $\mathrm{Cu}-\mathrm{Sn}$, segregation of tin from copper-based solid solution is not possible, i.e., such a process can take place only under strongly non-equilibrium conditions. Therefore, segregation of tin from a Cu-based solid solution is a nonspontaneous process, which is accompanied by an increase in free energy and negative entropy production. As such, this process can be considered self-organization. In order to increase the seizure load it's necessary to alloy tin bronze, so that self-organization (the precipitation of tin from a solid solution) proceeds under relatively light friction.

Acknowledgments: The work has been supported by grant of the Russian Science Foundation No. 14-19-01033 and 15-19-00217.

Author Contributions: Iosif S. Gershman performed the study conception and design; analyzed the data and wrote the manuscript together with German S. Fox-Rabinovich and Stephen C. Veldhuis; Eugeniy I. Gershman conceived and designed the experiments; Alexander E. Mironov performed the experiments as well as materials characterization. All authors have read and approved the final manuscript.

Conflicts of Interest: The authors declare no conflict of interest.

\section{References}

1. Klamecki, B.E. A thermodynamic model of friction. Wear 1980, 63, 113-120. [CrossRef]

2. Klamecki, B.E. Wear-An entropy production model. Wear 1980, 58, 325-330. [CrossRef]

3. Bershadsky, L.I. On self-organizing and concept of tribosystem. J. Frict. Wear 1992, 13, 101-114.

4. Klamecki, B.E. An entropy-based model of plastic deformation energy dissipation in sliding. Wear 1984, 96, 319-329. [CrossRef]

5. Klamecki, B.E. Energy dissipation in sliding. Wear 1982, 77, 115-128. [CrossRef]

6. Kondepudi, D.; Prigogine, I. Modern Thermodynamics, 1st ed.; Wiley: Hoboken, NJ, USA, 1998.

7. Gershman, I.S.; Bushe, N.A. Realization of dissipative self-organization on friction surface of tribosystems. J. Frict. Wear 1995, 16, 61-70.

8. Gershman, I.S. Formation of Secondary Structures and the Self-Organization Process of Tribosystems during Friction with the Collection of Electric Current. In Self-Organization during Friction; CRC Press: Boca Raton, FL, USA, 2006; pp. 197-230.

9. Dukhovskoi, E.A.; Ponomarev, A.N.; Silin, A.A.; Tal'roze, V.L. Effect of Anomaly Low Friction upon Electronic Bombardment of Rubbing Surface by Molybdenum Disulphide. Pis'ma v Zh. Eksp. i. Teor. Fiz. 1974, 20, 268-272. (In Russian).

10. Bogachev, I.M.; Mints, R.I. Increasing of Cavitation Resistance of Machine Parts; Mashinostroenie: Moscow, Russia, 1964. (In Russian)

11. Klimontovich, Yu.L. Introduction in Physics of Open Systems Coche; Yanus-K: Moscow, Russia, 2002. (In Russian)

12. Glansdorff, P.; Prigogine, I. Thermodynamic Theory of Structure, Stability and Fluctuations; Wiley: Hoboken, NJ, USA, 1971.

13. Heinecke, G. Tribochemistry; Akademie Verlag: Berlin, Germany, 1984.

14. Fox-Rabinovich, G.S.; Yamamoto, K.; Beake, B.D.; Gershman, I.S.; Kovalev, A.I.; Veldhuis, S.C.; Aguirre, M.H.; Dosbaeva, G.; Endrino, J.L. Hierarchical adaptive nanostructured PVD coatings for extreme tribological applications: The quest for non-equilibrium states and emergent behavior. Sci. Technol. Adv. Mater. 2012, 13, 043001. [CrossRef]

15. Bushe, N.A.; Gershman, I.S.; Mironov, A.E. Process of self-organizing tribosystems without and with current collection. In Proceedings of the 2nd World Tribology Congress, Vienna, Austria, 3-7 September 2001.

16. Nosonovsky, M. Entropy in tribology: In the search for applications. Entropy 2010, 12, 1345-1390. [CrossRef]

17. Ebeling, W.; Engel, A.; Feistel, R. Physik der Evolutionsprozesse; Akademie Verlag: Berlin, Germany, 1990. (In German) 
18. Gershman, J.S.; Bushe, N.A. Thin films and self-organization during friction under the current collection conditions. Surf. Coat. Technol. 2004, 186, 405-411. [CrossRef]

19. Gershman, I.S.; Bushe, N.A. Elements of Thermodynamics and Self-Organization during Friction. In Self-Organization during Friction; CRC Press: Boca Raton, FL, USA, 2006; pp. 13-58.

20. Landau, L.D.; Lifshitz, E.M. Statistical Physics, 3rd ed.; Butterworth-Heinemann: Oxford, UK, 1980.

21. Nikolis, G.; Prigogine, I. Self-Organization in Nonequilibrium Systems; Wiley: Hoboken, NJ, USA, 1977.

22. Bushe, N.A.; Gershman, I.S. Compatibility of Tribosystems. In Self-Organization during Friction; CRC Press: Boca Raton, FL, USA, 2006.

23. Gershman, I.S.; Gershman, E.I. Catalytic Effect during Friction. J. Frict. Wear 2011, 32, 431-436. [CrossRef]

24. De Groot, S.R.; Mazur, P. Non-Equilibrium Thermodynamics; North-Holland Publishing Corporation: Amsterdam, The Netherlands, 1962.

25. Fox-Rabinovich, G.; Kovalev, A.; Veldhuis, S.; Yamamoto, K.; Endrino, J.L.; Gershman, I.S.; Rashkovskiy, A.; Aguirre, M.H.; Wainstein, D.L. Spatio-temporal behaviour of atomic-scale tribo-ceramic films in adaptive surface engineered nano-materials. Sci. Rep. 2015, 5, 8780. [CrossRef] [PubMed]

26. Gershman, I.S.; Trushevskij, S.M.; Shumitskij, A.V. The role of carbon in self-organization of the process of wear of strong current sliding electrical contacts. J. Frict. Wear 2002, 23, 520-523.

(C) 2015 by the authors; licensee MDPI, Basel, Switzerland. This article is an open access article distributed under the terms and conditions of the Creative Commons by Attribution (CC-BY) license (http:/ / creativecommons.org/licenses/by/4.0/). 